\title{
Promesas y realidades: el fracaso del plan de salida de Estados Unidos de Afganistán (2009-2014)
}

\author{
Promises and realities: \\ The United States' failed \\ exit from Afghanistan (2009-2014)
}

\section{ENRIQUE BALTAR RODRÍGUEZ*}

Resumen: El presente artículo pretende demostrar que el grave deterioro de la seguridad en Afganistán, luego de la retirada de las fuerzas multinacionales comandadas por la Organización del Tratado del Atlántico Norte (OTAN) en diciembre de 2014, ha sido resultado inevitable del fracaso militar de la estrategia de salida de Estados Unidos. A través del análisis de indicadores relacionados con la violencia y la inseguridad en el país durante el periodo 2009-2014, el artículo sostiene que la estrategia militar diseñada por la administración Obama fracasó en el propósito de asegurar las premisas básicas para que el proceso de traspaso de responsabilidades al gobierno afgano se efectuara en un contexto de estabilidad política relativamente consolidado. En consecuencia, los niveles de violencia e inseguridad registrados después de 2014 forman parte de una misma tendencia de continuidad claramente establecida en años anteriores.

Palabras clave: Estados Unidos; Afganistán; estrategia militar; transición; inseguridad.

Recepción: 7 de junio de 2018. / Aceptación: 19 de octubre de 2018.

* Universidad de Quintana Roo, enbaltar@uqroo.edu.mx 
Abstract: This article aims to demonstrate that the drastic deterioration in Afghanistan's security situation following the withdrawal of the NATO-led multinational forces in December 2014 has been an inevitable result of the failure of the United States military's exit strategy. By analyzing a series of indicators related to the levels of violence and insecurity in the country between 2008 and 2014, the author of this article argues that the Obama administration's military strategy failed to create the conditions for an orderly transfer of responsibilities to the Afghan government within a context of relatively consolidated political stability. As a result, the spiralling violence and insecurity since 2014 continue a trend clearly established in previous years.

Keywords: United States; Afghanistan; military strategy; transition; insecurity.

Días antes del inicio de la campaña militar de Estados Unidos en Afganistán a principios de octubre de 2001, el líder del régimen talibán hizo una declaración que se volvió premonitoria del curso de los acontecimientos posteriores: "América nos promete la derrota y Dios nos promete la victoria, veremos cuál de las dos promesas se cumple" (Joscelyn y Roggio, 2015). ${ }^{1}$

La rápida caída del régimen talibán ante el arrollador empuje de las fuerzas de la coalición alimentó la ilusión de un arranque triunfal en la guerra contra el terrorismo, la cual muy pronto devino en una desgastante confrontación asimétrica y en una prolongada presencia militar extranjera en el país. Inicialmente investidas por el Consejo de Seguridad con un mandato de seis meses en diciembre de 2001, las Fuerzas Internacionales para la Asistencia a la Seguridad de Afganistán

${ }^{1}$ Al parecer, la frase citada por los periodistas del New York Times no es textual, sino una interpretación de lo expresado por el mulá Omar en una entrevista concedida en pasto al canal de radio Voice of America el 26 de septiembre de 2001. De acuerdo con una transcripción de lo registrado, a la pregunta de si sabía que Estados Unidos había anunciado una guerra contra el terrorismo, el líder talibán contestó: "Estoy considerando dos promesas. Una es la promesa de Dios, la otra es la de Bush. La promesa de Dios es que mi tierra es enorme. Si comienzas un viaje en el camino de Dios, puedes residir en cualquier lugar de esta tierra y estarás protegido. La promesa de Bush es que no hay lugar en la tierra donde puedas esconderte que no pueda encontrarte. Veremos cuál de estas dos promesas se cumple” (Mullah Omar-in his own words, 26 de septiembre de 2001). 
(FIAS) tuvieron que prolongar su presencia durante 13 años, hasta diciembre de 2014, fecha en que concluyó oficialmente su misión. En la segunda mitad de ese dilatado mandato, el desempeño de la fuerza multinacional estuvo marcado por tres procesos importantes dirigidos a garantizar el éxito en la lucha contra el terrorismo y la insurgencia islamista.

El primer proceso fue la incorporación de las tropas de la coalición (fuerza autónoma dedicada a operaciones de contrainsurgencia y compuesta básicamente por efectivos de Estados Unidos) a la estructura de las FiAs bajo la coordinación de un mando militar único liderado por la OTAN. A partir de ese momento, la jefatura del comando conjunto quedó en manos de Estados Unidos y sus fuerzas militares adquirieron un peso determinante en la composición de las FIAS. El segundo tuvo que ver con el nuevo rumbo marcado por la estrategia de la administración del presidente Barack Obama, que presupuso el itinerario a mediano plazo de un plan de salida de Afganistán para finales de 2014. Y el tercero fue la concertación de los dos acuerdos de seguridad suscritos por el gobierno afgano con Estados Unidos y la OTAN, respectivamente, que establecieron los compromisos de las partes para garantizar la seguridad del país después de la retirada de las fuerzas multinacionales.

Sin embargo, a pesar de los esfuerzos realizados, el escenario afgano post-2014 se ha caracterizado por una fuerte espiral de violencia y un agravamiento sostenido de la inseguridad interna. Ese deterioro de la situación podría explicarse, al menos, desde dos perspectivas argumentales diferentes. La primera es considerar que hubo un retroceso, visión implícita, por ejemplo, en los informes cuatrimestrales del secretario general al Consejo de Seguridad de la ONU sobre la situación en Afganistán (ONU, 2014; 2015). En este caso, la argumentación supondría que, hasta diciembre de 2014, la estrategia antiterrorista fue relativamente exitosa, pero, tras la retirada de las FIAs, las condiciones se tornaron favorables para que una insurgencia talibán duramente golpeada en los años anteriores volviera a reagruparse y recuperara fuerzas. En este primer escenario, la incapacidad del gobierno afgano y el incumplimiento de Estados Unidos y la OTAN de los compromisos de seguridad constituirían factores explicativos muy importantes. La otra perspectiva, en cambio, 
tiende a ver el deterioro como una tendencia de continuidad que sólo se potenció después de la retirada de las fuerzas multinacionales. En este segundo escenario, el análisis apuntaría hacia el enjuiciamiento crítico de una estrategia militar que, a contrapelo de su narrativa triunfalista, fracasó en el propósito esencial de acabar con la amenaza talibán. La hipótesis central de este artículo se enmarca en esa segunda línea argumental, por lo que a continuación se delimitarán con mayor precisión el punto de partida y la metodología de sustentación.

\section{Descripción del problema y metodología}

La idea central que se pretende demostrar es que el detrimento creciente de la seguridad constituyó un resultado inevitable del fracaso militar de la estrategia de salida de Estados Unidos. Desde la segunda mitad de 2011, momento en que se inició el traspaso gradual de responsabilidades a las Fuerzas de Seguridad Afganas (FSA), hasta diciembre de 2014, en que concluyó formalmente la misión de las FIAs, hubo numerosas señales que permitían suponer - con muchas probabilidades de acertarque el plan militar diseñado por la administración Obama había fallado en asegurar las premisas básicas para que la retirada se efectuara en un contexto de estabilidad política relativamente consolidado. En consecuencia, la salida se consumó de acuerdo con el itinerario previsto, no porque hubiera alcanzado sus objetivos, sino a pesar de su eventual fracaso, debido a la conveniencia política de cerrar un costoso y largo capítulo de ocupación militar que suponía ya un tema muy controversial en Estados Unidos, en la política interna afgana y en la agenda de la relación bilateral.

Este artículo se centra sólo en la primera parte de la afirmación anterior, es decir, en la evaluación de los resultados de la estrategia diseñada para preparar el camino hacia la retirada militar de Estados Unidos, la cual fue definida e instrumentada por la administración de Barack Obama a partir de $2009 .^{2} \mathrm{La}$

${ }^{2}$ La segunda parte, referida a la conveniencia política de concluir la ocupación, tiene en este caso sólo el valor de una inferencia subsidiaria que debe ser tratada a profundidad en otro momento. 
intervención en Afganistán fue una herencia incómoda que esa administración intentó reconfigurar estratégicamente (Rafique, 2011, p. 129). Durante los dos mandatos presidenciales de George W. Bush, Afganistán pasó de ser el centro emblemático de la nueva guerra contra el terrorismo a convertirse en un escenario secundario tras la agresión a Iraq en 2003. El empantanamiento en una difícil empresa de pacificación en Iraq acaparó la atención política del gobierno de Estados Unidos y también el grueso de sus recursos financieros y militares.

Gráfica 1. Gastos de Estados Unidos en las guerras de Afganistán e Iraq (miles de millones de USD)

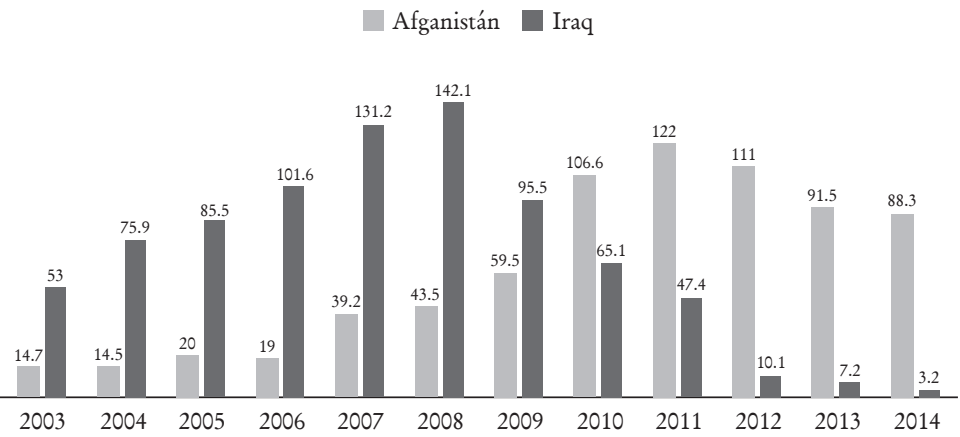

Fuente: Statista, 2018.

Como se aprecia en la gráfica 1, durante la administración republicana los gastos anuales de la campaña militar en Iraq siempre superaron, cuando menos en tres veces, los recursos destinados a la guerra contra el terrorismo en Afganistán. En 2006 esa proporción se elevó hasta 5.3 veces, justo en el año en que la amplitud de la ofensiva de primavera emprendida por el talibán en el sur de Afganistán comenzó a evidenciar el peligroso repunte de la insurgencia islamista a lo largo de la frontera afgano-pakistaní. Aunque en términos brutos el gasto de 2007 en Afganistán se duplicó respecto al año anterior, siguió representando 3.3 veces menos que el destinado a Iraq y en 
2008 observó el mismo comportamiento a pesar de que, para ese entonces, la seguridad en Afganistán estaba deteriorándose drásticamente.

Esa situación convirtió las políticas hacia Iraq y Afganistán en punto importante de los debates durante la campaña presidencial de 2008, en los que Barack Obama criticó fuertemente la línea republicana y posicionó con bastante éxito la idea de la revaloración estratégica de Afganistán. En consecuencia, a su llegada a la Casa Blanca, aceleró la instrumentación de una estrategia de salida de Iraq, considerada entonces una "guerra de elección” del gobierno anterior, para concentrar la atención nuevamente en Afganistán, donde el deterioro de la seguridad y el repunte de la insurgencia islamista y de la actividad terrorista reafirmaban el escenario como la verdadera "guerra de necesidad" para los intereses y la seguridad de Estados Unidos (Obama, 2009a).

A partir de 2010 se invirtió claramente la tendencia en la proporción de los gastos militares en ambos países (gráfica 1) y hacia 2011, año clímax de la estrategia de Obama desde el punto de vista del esfuerzo bélico, el gasto en Afganistán alcanzó un nivel bastante cercano a los más altos registrados en Iraq unos años antes. Esos datos apuntan a una importante revaloración estratégica del escenario afgano y confirman que la nueva administración demócrata, como nunca antes, destinó cuantiosos recursos a neutralizar la amenaza talibán, consolidar el gobierno afgano y preparar las condiciones para el traspaso de poderes.

La afirmación anterior justifica la decisión metodológica de limitar el marco de referencia temporal de este artículo al periodo 2009-2014 y de estructurar su contenido en dos apartados principales. El primero se refiere a la descripción del objeto de estudio, es decir, la estrategia de la administración Obama hacia Afganistán, con el propósito de establecer un contexto comprensible y definido dentro del cual puedan insertarse los elementos de valoración posteriores. El segundo está dedicado a la evaluación de los resultados a fin de determinar hasta qué punto la estrategia consiguió, efectivamente, asegurar las condiciones para una transición responsable y de bajo riesgo. En este apartado se consideró procedente la revisión de indicadores para respaldar la reflexión con expresiones cuantitativas verifi- 
cables y sistematizadas en series estadísticas que permitan seguir los comportamientos tendenciales. Aunque en este caso las posibilidades del universo estadístico son muy restringidas, el análisis se apoya en varios indicadores generados por fuentes oficiales cuya información proviene de la presencia directa en Afganistán (Misión de Asistencia de las Naciones Unidas en Afganistán, Organización del Tratado del Atlántico Norte, Oficina de las Naciones Unidas contra la Droga y el Delito, Alto Comisionado de las Naciones Unidas para los Refugiados e Inspección General Especial para la Reconstrucción de Afganistán) y que están, además, disponibles para consulta pública.

En general, los indicadores seleccionados reflejan de diversas maneras la violencia y la inseguridad en el país, aunque probablemente resulte discutible su adscripción a un mismo modelo de seguridad si se tiene en cuenta la multiplicidad del concepto y sus especificaciones divergentes (Baldwin, 1997). Hasta el final de la Guerra Fría, el contenido del concepto de seguridad estuvo totalmente dominado por un enfoque realista centrado en el interés nacional y en la defensa del Estado. Desde la década de 1990, sin embargo, los cambios en la realidad internacional generaron la necesidad de nuevas aproximaciones teóricas para resolver la aplicación ambigua del término en un contexto caracterizado por la valoración de otros actores y percepciones de amenazas (Orozco, 2006). Desde entonces, el debate en torno al concepto ha dado paso a visiones menos restrictivas que restan peso al Estado como destinatario principal de la seguridad para enfatizar la importancia de la seguridad en el plano societal e individual desde una perspectiva de los derechos humanos (Van Kempen, 2013).

Entre esos enfoques menos restrictivos cabe mencionar en particular los de "seguridad democrática" y "seguridad humana" por las posibilidades que ofrecen para encuadrar los indicadores seleccionados en un marco conceptual determinado. El primero remite a un modelo de seguridad en países que, como Afganistán, están tratando de superar situaciones de conflicto y han emprendido procesos de transición política bajo las expectativas de consolidación y estabilidad del sistema democrático. En este caso, la seguridad está encaminada a la contención de amenazas que puedan poner en peligro esa estabilidad democrática y la 
integridad funcional de la sociedad (Orozco, 2006, p. 174). En ese sentido, algunos de los indicadores seleccionados - promedio mensual de incidentes de seguridad, incidentes de seguridad durante las campañas de primavera-verano, cantidad de efectivos militares, cantidad de bajas de efectivos militares y niveles de producción de opio- pueden contribuir a dar una idea más clara tanto de la persistencia y la intensidad de esas amenazas como de la capacidad del gobierno afgano para neutralizarlas.

Por su parte, el concepto de "seguridad humana" pone el énfasis en la protección de las personas en situaciones que amenazan o violan sus derechos humanos. Los tres indicadores restantes utilizados en este estudio - cantidad de víctimas civiles causadas por el conflicto, de víctimas civiles causadas por choques armados directos y de desplazados internos- entran evidentemente en esta definición, aunque vale agregar que esa línea divisoria, desde mi punto de vista, resulta bastante endeble por el peso que ambos modelos de seguridad confieren a la protección de los derechos humanos. La preservación de la estabilidad democrática sólo es posible si la integridad y los derechos de los ciudadanos están debidamente protegidos y, por tanto, las amenazas o las violaciones a esos derechos por lo general ocurren por la incapacidad gubernamental para enfrentar y contener los peligros que ponen en riesgo el orden y el Estado de derecho. Ésa es la razón principal que relaciona los indicadores seleccionados y los coloca en una misma perspectiva argumental, cuya visión de conjunto aporta suficientes evidencias empíricas para demostrar la hipótesis planteada.

\section{Estrategia de la administración Obama hacia Afganistán: antecedentes y rasgos principales}

Hacia finales de 2008 y principios de 2009, el deterioro de la seguridad en Afganistán había alcanzado proporciones alarmantes. Algunas zonas habían vuelto a caer en manos del talibán y las amenazas de riesgo extremo y alto afectaban a 175 de los 400 distritos del país (ONU, 2009a, p. 6). En 20072008, la producción de opio alcanzó también los niveles más altos del periodo, sobre todo en las provincias del sur-sureste 
MAPA 1. Seguridad y producción de opio en Afganistán (2008)

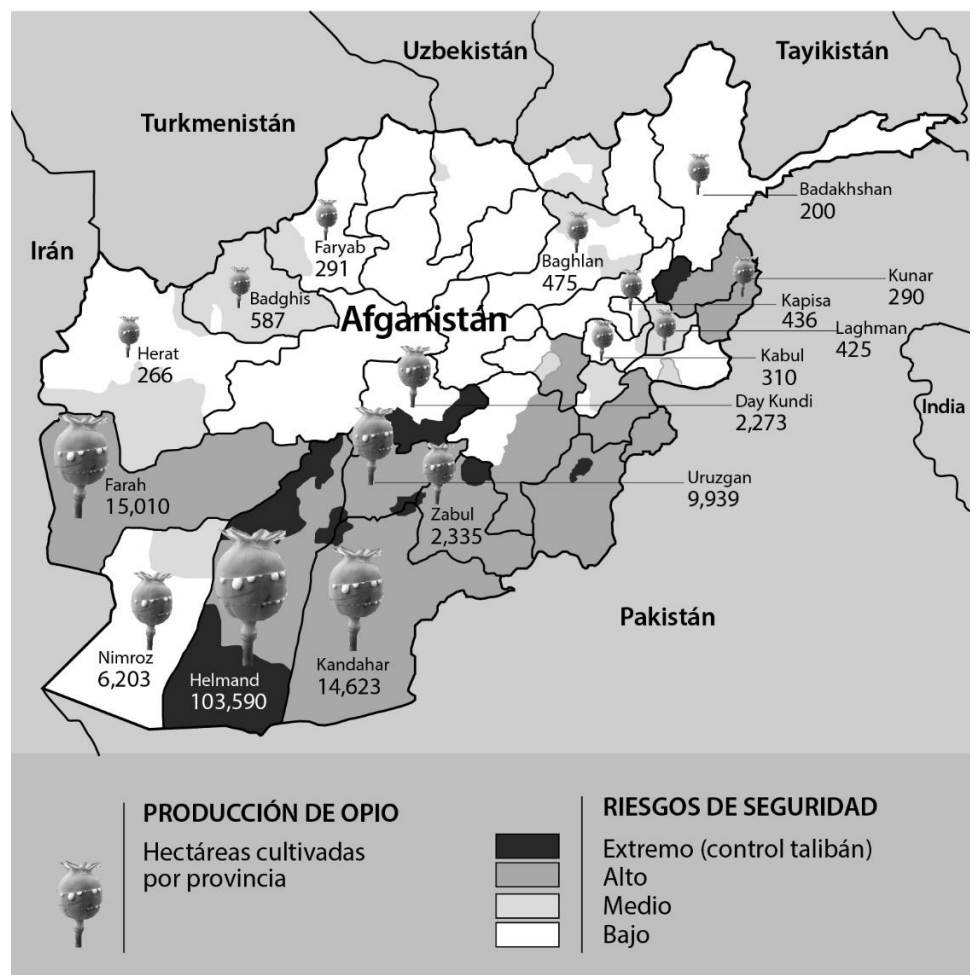

Fuente: Elaboración propia con información del Ministerio del Interior de Afganistán/Reuters, 2009; y UNODC, 2009, pp. 12-14.

del país, principal escenario de operaciones de la insurgencia y donde estaban destacados los tres (de cinco) comandos más importantes de las Fuerzas Internacionales de Asistencia a la Seguridad.

Del otro lado de la Línea Durand, la insurgencia islamista también experimentaba una peligrosa escalada. Las hostilidades en Waziristán habían cobrado fuerza desde finales de 2007 y muchos grupos rebeldes originarios de las Áreas Tribales Fe- 
deralmente Administradas (FATA) se agruparon en el Tehrik-eTaliban Pakistan (TTP), más conocido como talibán pakistaní, con una estructura autónoma pero estrechamente coordinado, en lo operativo, con el talibán afgano y Al Qaeda para lanzar ataques contra las fuerzas de la OTAN en Afganistán y también contra el ejército pakistaní en territorio propio. Hacia 2008, las acciones ofensivas del TTP habían desbordado las fronteras de las FATA y se extendían a lo largo del valle de Swat, en pleno territorio de la entonces Provincia de la Frontera del Noroeste y en franco desafío a la autoridad del gobierno central de Islamabad. Todo ello estaba configurando la frontera afgano-paquistaní como el lugar más peligroso, violento e inseguro del mundo (Gul, 2009; Nawaz, 2009).

El creciente deterioro de las condiciones de seguridad reflejaba con singular crudeza las debilidades del proceso de transición afgano y los enormes contrastes entre las realidades regionales. Por su condición de capital y sede del gobierno central, así como de la Misión de Asistencia de las Naciones Unidas en Afganistán y de las FIAs, Kabul había sido desde el inicio la vitrina de la transición política, donde se movían con mayor rapidez los nuevos procesos de cambio y el ambiente de seguridad estaba relativamente más controlado. Pero en el resto de las provincias la dinámica política era mucho más compleja, los beneficios de la paz parecían menos tangibles y la resistencia de las estructuras tradicionales a los cambios era mucho mayor. El lento avance del programa de desmovilización y desarme de los grupos armados y el fracaso de la estrategia antidroga contribuyeron a que muchos jefes muyahidines y señores de la guerra conservaran en buena medida las bases de su poder provincial y local. Después de siete años de transición, la situación de seguridad no dejaba dudas en cuanto a que el mayor desafío del gobierno afgano seguía siendo su incapacidad para hacer valer su autoridad política, administrativa y militar en todo el territorio del país.

A su vez, dentro del heterogéneo horizonte regional, había diferencias notables entre las provincias del centro-norte del país y las del sur-sureste. En las primeras, las amenazas a la gobernabilidad estaban más relacionadas con los intereses de los viejos caudillos muyahidines, que seguían conservando 
mucha influencia local, y con las rivalidades étnicas por la redistribución del poder entre las facciones tayika, uzbeca y házara, que tuvieron un peso muy importante en la lucha contra el régimen talibán, y entre todas ellas con el predominante grupo pastún, encabezado por el presidente Hamid Karzai, que trataba de recuperar su posición histórica en el poder central. En cambio, en las segundas, que abarcan la gran franja pastún del país donde estaba la principal base de apoyo del régimen anterior, los riesgos a la seguridad estaban asociados directamente al resurgimiento de una insurgencia talibán opuesta a la ocupación extranjera y al nuevo gobierno afgano considerado una imposición de Estados Unidos.

Varios factores contribuyeron a potenciar esa situación de riesgo. En las provincias del sur estaba concentrada la mayor parte de la producción de opio, sobre todo en Helmand y Kandahar, región de origen del movimiento talibán, circunstancia que proporcionaba a la insurgencia una significativa fuente de financiamiento. La capacidad militar del gobierno de Hamid Karzai era muy insuficiente debido al lento avance del programa para la formación del Ejército Nacional Afgano, que distaba mucho de tener los efectivos, los recursos y la preparación necesarios. Fuera de Kabul, el papel de las FIAS estaba prácticamente limitado a la participación en los Equipos de Reconstrucción Provincial en zonas de bajo riesgo, porque la mayoría de los países que integraban las fuerzas multinacionales se mostraban reacios a tomar parte en misiones combativas, las cuales estaban a cargo de una fuerza reducida de la coalición compuesta esencialmente por soldados estadounidenses. Por último, la porosidad de la frontera y el peligroso doble juego de los círculos militares y de inteligencia de Pakistán también conspiraban contra la efectividad de las estrategias antiterroristas, al permitir que el talibán siguiera contando con bases de apoyo en la retaguardia, a contrapelo de los reproches y las presiones de Estados Unidos y Afganistán (Baltar, 2018).

Al llegar a la Casa Blanca, el presidente Barack Obama asumió la decisión de reforzar el compromiso con Afganistán para revertir la grave situación de seguridad y crear las condiciones para una retirada militar a mediano plazo. La esencia de su política fue anunciada en diciembre de 2009 en un discurso 
pronunciado en la Academia Militar de West Point: "Éstos son los tres elementos centrales de nuestra estrategia: un esfuerzo militar [surge] que prepare las condiciones para una transición, un impulso civil que refuerce la acción positiva, y una asociación efectiva con Pakistán” (Obama, 2009b). La nueva estrategia debía asegurar el objetivo principal de vencer a Al Qaeda y quitarle la capacidad de amenazar en el futuro a Estados Unidos y sus aliados, así como frenar el avance del talibán e impedir que adquiriera fuerza para derrocar al gobierno de Hamid Karzai. En consecuencia, el peso fundamental recayó sobre las cuestiones de seguridad y los otros dos pilares de la estrategia fueron concebidos como potenciadores necesarios de la eficacia del componente militar.

Estados Unidos y sus aliados de la OTAN concordaron en la necesidad de orientar el esfuerzo integrado de las FIAS en dos direcciones principales: un significativo incremento de tropas para lanzar un demoledor golpe militar contra Al Qaeda y el talibán, y una acelerada preparación de las FSA como premisa para el posterior traspaso de responsabilidades y la reducción gradual de las tropas multinacionales. La esencia de la estrategia quedó resumida en tres palabras claves: surge, transition y drawdown.

El cuadro 1 refleja con bastante claridad la hoja de ruta de la estrategia militar de la administración Obama y el decisivo papel de las tropas estadounidenses. Hasta finales de 2008, su presencia militar no llegaba a los 20000 soldados. En el primer año de Obama la cantidad de efectivos experimentó un aumento moderado que se convirtió en significativo en los dos años siguientes que correspondieron a la etapa intensiva del esfuerzo militar. La ofensiva contrainsurgente de las fuerzas coordinadas por la OTAN (surge) se programó para una duración de 18 meses, desde enero de 2010 hasta junio de 2011, periodo en el que las tropas estadounidenses aumentaron de 31855 a 90000 soldados, y la capacidad total de las FIAs creció de 67700 a 132381 efectivos procedentes de 48 países. A su vez, la tendencia decreciente que se aprecia desde la segunda mitad de 2012 refleja el proceso de transferencia de responsabilidades a las FSA y la retirada gradual de los contingentes de las FIAS que concluyó oficialmente en diciembre de 2014. 


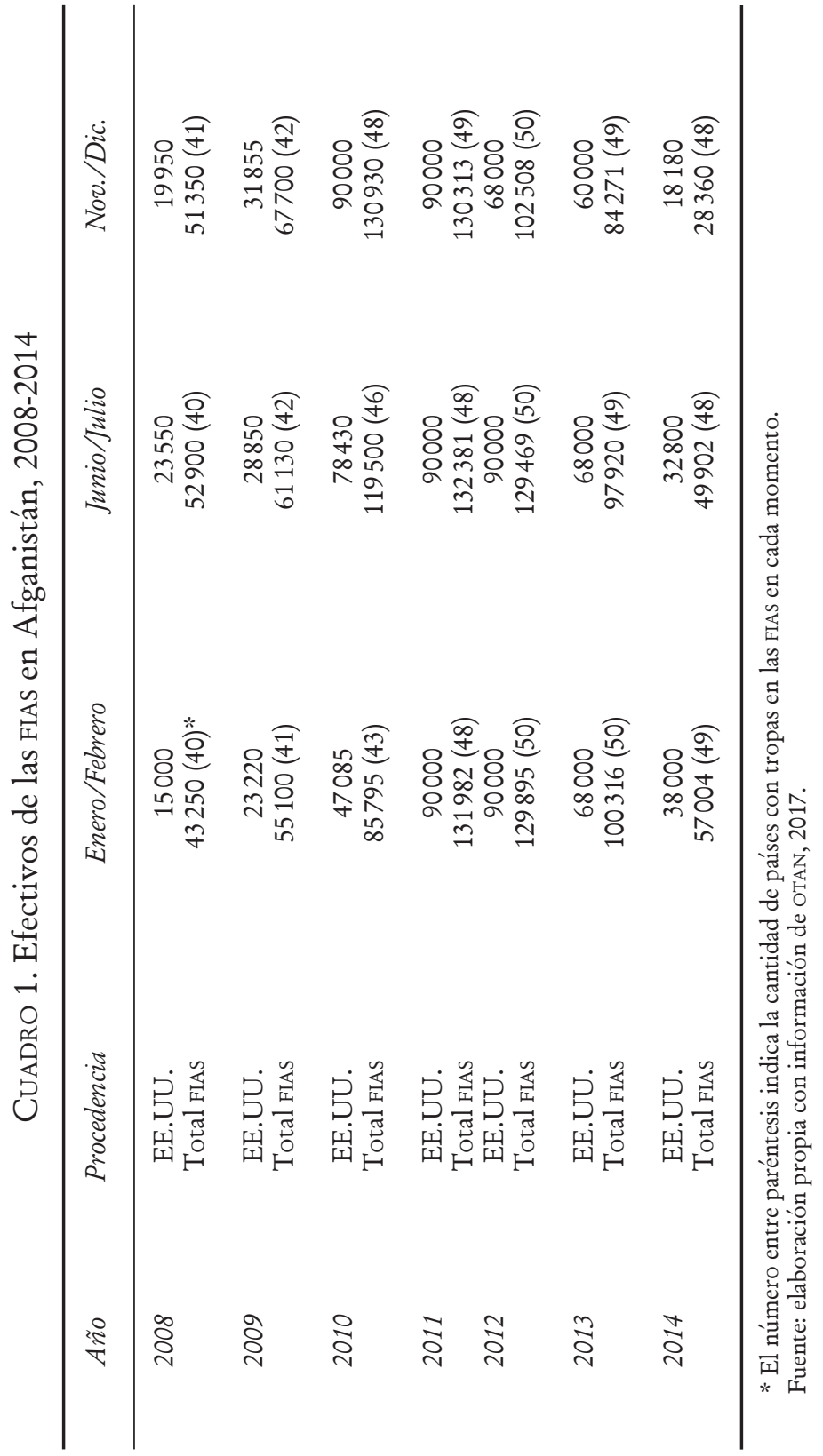


Desde la primera campaña de primavera en 2010 quedó evidenciado, sin embargo, que el optimismo político de la Casa Blanca no era del todo compartido por el alto mando militar en Afganistán, cuya apreciación de la situación resultaba más pesimista, pues al tener una visión diferente de las complejidades del escenario, consideraba que la campaña para neutralizar al talibán requeriría de más recursos, más tropas y, sobre todo, de mucho más tiempo (Katzman y Thomas, 2017, p. 24). En lugar de contribuir a corregir el rumbo de la estrategia, la diferencia de percepciones sirvió para enturbiar las relaciones civiles-militares, contradicción que alcanzó su clímax en junio de 2010 con la dimisión del general Stanley MacChrystal como jefe del comando conjunto de la OTAN y Estados Unidos en Afganistán. El general David Petraeus asumió el mando en julio de 2010 y tuvo a su cargo la dirección del resto de la ofensiva militar en medio de un creciente menoscabo de las relaciones Washington-Islamabad. ${ }^{3}$

A partir de 2009, la preparación de las FSA entró asimismo en una etapa de fuerte crecimiento a través de sus dos grandes componentes: el Ejército Nacional Afgano (ENA) y la Policía Nacional Afgana (PNA). Desde 2012, la pequeña Fuerza Aérea Afgana (FAA) comenzó a figurar también como un cuerpo diferenciado, ya que hasta entonces había estado integrada al ENA. Debido a la amenaza de la oposición armada, el interés fundamental se centró en el fortalecimiento del ENA, adonde

${ }^{3}$ La relación con Pakistán también planteó un temprano desafío a la estrategia en Afganistán. La intención de la Casa Blanca de fortalecer la alianza con su controversial socio en la guerra contra el terrorismo, mediante el otorgamiento de un cuantioso paquete de asistencia financiera, no logró los resultados esperados. Los condicionamientos establecidos por la Ley Kerry-Lugar-Berman (2009) fueron mal recibidos por la mayoría de la opinión pública pakistaní, y sobre todo por el poderoso sector militar. El sentimiento antinorteamericano se hizo cada vez más fuerte debido al incremento de los ataques con drones en la región de las FATA y a una cadena de sucesos ocurridos en 2011 (caso del agente de la CIA Raymond Davis, operativo de Abbottabad para capturar a Osama bin Laden, escándalo del Memogate e incidente de Salala) que desembocaron en una profunda crisis a finales de 2011. El duelo de represalias llevó la relación a su nivel más bajo por alrededor de un año, durante el cual el gobierno de Islamabad cerró el paso de Kyber, principal vía de abastecimiento de la OTAN en Afganistán, y la Casa Blanca respondió congelando la asistencia militar. La interrupción de la colaboración ocurrió en el momento de culminación del surge y el inicio del proceso de transición en Afganistán; este aspecto es tratado con más profundidad en Baltar, 2018. 
fue a parar más de la mitad de la asistencia financiera estadounidense. Como en otros escenarios de posconflicto, en Afganistán el ejército tuvo una clara preeminencia desde el principio (Jalali, 2016, p. 8). El programa para la formación de un ejército nacional quedó bajo la responsabilidad de Estados Unidos y fue establecido desde el comienzo de la transición política en 2002. En aquel entonces, la Misión de Asistencia de las Naciones Unidas en Afganistán determinó que el país necesitaría un ejército de 70000 efectivos para garantizar la seguridad interna y estableció un plazo de dos años para desarrollar el programa.

Cuadro 2. Crecimiento de las Fuerzas de Seguridad Afganas (FSA), 2008-2014

\begin{tabular}{lrrrrrrr}
\hline & $2008^{*}$ & 2009 & 2010 & 2011 & 2012 & 2013 & 2014 \\
\hline Efectivos ENA & 620000 & 100131 & 149553 & 176354 & 174645 & 178816 & 178617 \\
Efectivos PNA & 57400 & 94958 & 115584 & 143797 & 151080 & 149466 & 153317 \\
Efectivos FAA ** & - & - & - & - & 5872 & 6570 & 6922 \\
Total FSA & 119400 & 195089 & 265137 & 320151 & 331597 & 334852 & 338856 \\
\hline
\end{tabular}

ENA: Ejército Nacional Afgano; PNA: Policía Nacional Afgana; FAA: Fuerza Aérea Afgana.

* Las cifras de 2008 son aproximadas (ONU, 2008, p. 7).

** Hasta 2011, las cifras del ENA incluían al personal de la FAA.

Fuente: elaboración propia con información de SIGAR, 2010, p. 60; 2011, p. 53; 2012, p. 76; 2013, p. 73; 2014a, p. 85; 2014b, p. 92.

Durante los cinco primeros años de la transición política, el crecimiento del ENA fue mucho más lento de lo esperado y, como se aprecia en el cuadro 2, en 2008 aún no había alcanzado la meta proyectada inicialmente. Para ese entonces, sin embargo, las estimaciones estratégicas habían cambiado drásticamente respecto a la perspectiva de 2002. El creciente deterioro de la situación contribuyó a modificar una y otra vez las estimaciones sobre el tamaño de las fuerzas de seguridad necesarias para asumir la protección del país y, dentro de esa espiral, el crecimiento real de las FSA siempre estuvo a la zaga de los nuevos requerimientos. En 2009, por ejemplo, la plantilla registrada del ENA había rebasado ya los 100000 efectivos, pero 
esa cantidad representaba sólo $75 \%$ del nuevo total autorizado para ese año (134000). En junio de 2011, en vísperas del inicio del proceso de traspaso, la estimación sobre el tamaño requerido del ENA aumentó de nueva cuenta a 195000 efectivos, de los cuales 187000 corresponderían al ejército y 8000 a la fuerza aérea (SIGAR, 2013, p. 73).

Independientemente de esas dificultades, sobre las que se volverá en el siguiente apartado, el incremento de las FSA fue muy significativo desde el punto de vista cuantitativo en el periodo 2009-2014. Como refleja el cuadro 2, el mayor crecimiento del ENA y la PNA ocurrió entre 2009 y 2011, en el momento de apogeo del surge previo al inicio del traspaso de responsabilidades. Hacia finales de 2011, cuando comenzó el proceso de transición, las FSA tenían una capacidad nominal de 320000 efectivos, casi el triple de la cantidad disponible en 2008. Para finales de 2014, el ENA reportaba un completamiento de $95.5 \%$ (178617 efectivos de los 187000 autorizados), la PNA alcanzaba casi $98 \%$ (153317 de 157000 ) y la FAA, 86.5\% (6922 de 8000). Al término de la misión de las fuerzas multinacionales, las FSA en su conjunto reportaban tener $96 \%$ de los 352000 efectivos considerados necesarios para garantizar la protección del país (SIGAR, 2014b, p. 92).

La administración del presidente Obama destinó gran cantidad de recursos para impulsar el crecimiento y la preparación de las FSA. Desde el inicio de la transición política no sólo los programas relacionados con la seguridad, sino también los referidos a la reconstrucción nacional, y hasta gran parte de los gastos de operación del gobierno afgano, han dependido abrumadoramente del financiamiento internacional. Hasta 2014, la mayoría de las contribuciones aportadas por los donantes internacionales engrosaban los dos fondos administrados por la Misión de Asistencia de las Naciones Unidas en Afganistán: el Afghanistan Reconstruction Trust Fund, que a su vez está dividido en dos partes, una destinada a cubrir gastos de funcionamiento del gobierno afgano y otra para promover los programas de desarrollo; y el Law and Order Trust Fund, creado para apoyar la operación del Ministerio del Interior afgano y pagar los salarios del personal de la PNA. Aunque Estados Unidos ha sido el mayor contribuyente a los fondos internacionales, el 
GRÁFICA 2. Fondos para la reconstrucción de Afganistán

\section{Estados Unidos}

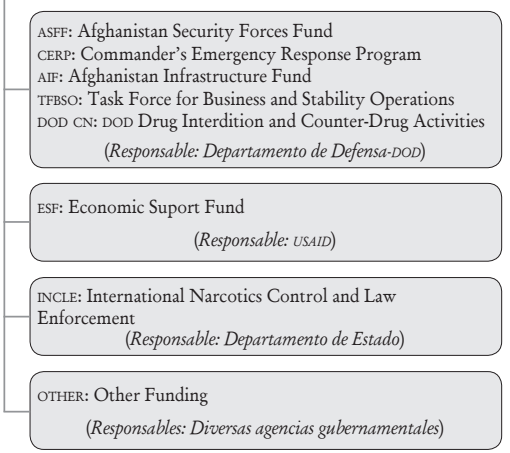

\section{Internacionales (UNAMA)}

ARTF: Afghanistan Reconstruction Trust Fund

- Recurrent Cost (RC) Window: Gastos de operación del gobierno afgano

- Invesment Window: Programas de desarrollo

LOTFA: Law and Order Trust Fund

(Pago de salarios de la PNA y operación del Ministerio del Interior)

Fuente: elaboración propia con información de SIGAR, 2015.

grueso de su ayuda financiera fluye a través de fondos propios administrados directamente por determinadas dependencias o agencias gubernamentales (gráfica 2).

De los ocho fondos destinados a la reconstrucción de Afganistán, cinco son administrados por el Departamento de Defensa, uno por el Departamento de Estado, otro por la Agencia de Estados Unidos para el Desarrollo Internacional y el octavo cruza de manera transversal diversas agencias gubernamentales. Los recursos asignados a esos fondos se clasifican básicamente en cuatro rubros o categorías de acuerdo con los objetivos a los que son destinados: seguridad, gobernanza y desarrollo, asistencia humanitaria y operaciones civiles (cuadro 3).

Del análisis del cuadro 3 se desprenden varias ideas importantes. De 2009 a 2014, el total de los recursos financieros suministrados por la administración Obama para apoyar la reconstrucción en Afganistán ascendió a 74105.78 millones de dólares, una cantidad 2.5 veces mayor que la otorgada en el periodo 2002-2008. Tan sólo en los tres primeros años de la presidencia de Obama (2009-2011) se destinaron más recursos a Afganistán que durante los dos mandatos anteriores de George W. Bush. En el segundo trienio (2012-2014), la ayuda financiera también superó el total del periodo 2002-2008, aunque 
CuAdro 3. Aportaciones de Estados Unidos por categorías (millones de USD)

\begin{tabular}{lrrrrrrr}
\hline & $2002-2008$ & 2009 & 2010 & 2011 & 2012 & 2013 & 2014 \\
\hline Seguridad & 15452.85 & 5838.40 & 9560.80 & 11000.67 & 9674.16 & 5203.44 & 4069.15 \\
$\begin{array}{l}\text { Gobernanza } \\
\text { y desarrollo }\end{array}$ & 10714.62 & 3287.06 & 5185.92 & 3674.00 & 3329.08 & 2951.82 & 1490.92 \\
$\begin{array}{l}\text { Humanitaria } \\
\text { Operaciones }\end{array}$ & 1587.41 & 293.96 & 176.90 & 190.24 & 268.85 & 157.09 & 182.74 \\
$\begin{array}{l}\text { civiles } \\
\text { Total }\end{array}$ & 1331.64 & 1091.06 & 1796.10 & 942.30 & 1484.38 & 1332.74 & 923.95 \\
\hline
\end{tabular}

Fuente: elaboración propia con información de SIGAR, 2015, pp. 198-199.

vale destacar que, respecto al trienio anterior, siguió una clara tendencia descendente, lo que parece indicar que la etapa de la transferencia de poderes presupuso no sólo el repliegue gradual de las fuerzas multinacionales, sino también una reducción sostenida de la asistencia financiera.

Al igual que su predecesora, la administración Obama privilegió el apoyo a la seguridad y le reservó un peso todavía mayor en el total de la asistencia financiera. En el periodo 20022008 se destinaron al rubro de seguridad 15452.85 millones de dólares, cantidad que representó $53.12 \%$ del total. Durante los años 2009-2014, el apoyo a la seguridad ascendió a 45346.62 millones de dólares, casi el triple del ciclo anterior, y su peso en el total alcanzó en promedio $60.5 \%$, con un máximo en 2011 , fecha en que ese rubro llegó a cubrir casi $70 \%$ del total de la ayuda financiera otorgada.

En esa clara preeminencia del financiamiento a la seguridad, destaca el peso determinante del Afghanistan Security Forces Fund (ASFF) como el mayor de los cinco fondos controlados por el Departamento de Defensa. Creado en 2005, el ASFF ha sido el canal encargado de proveer al ENA y la FAA los recursos para su formación, equipamiento y sostenimiento (cuadro 4).

En 2005-2008, el ASFF concentró poco más de la mitad del total de la ayuda y casi $90 \%$ de la destinada específicamente 


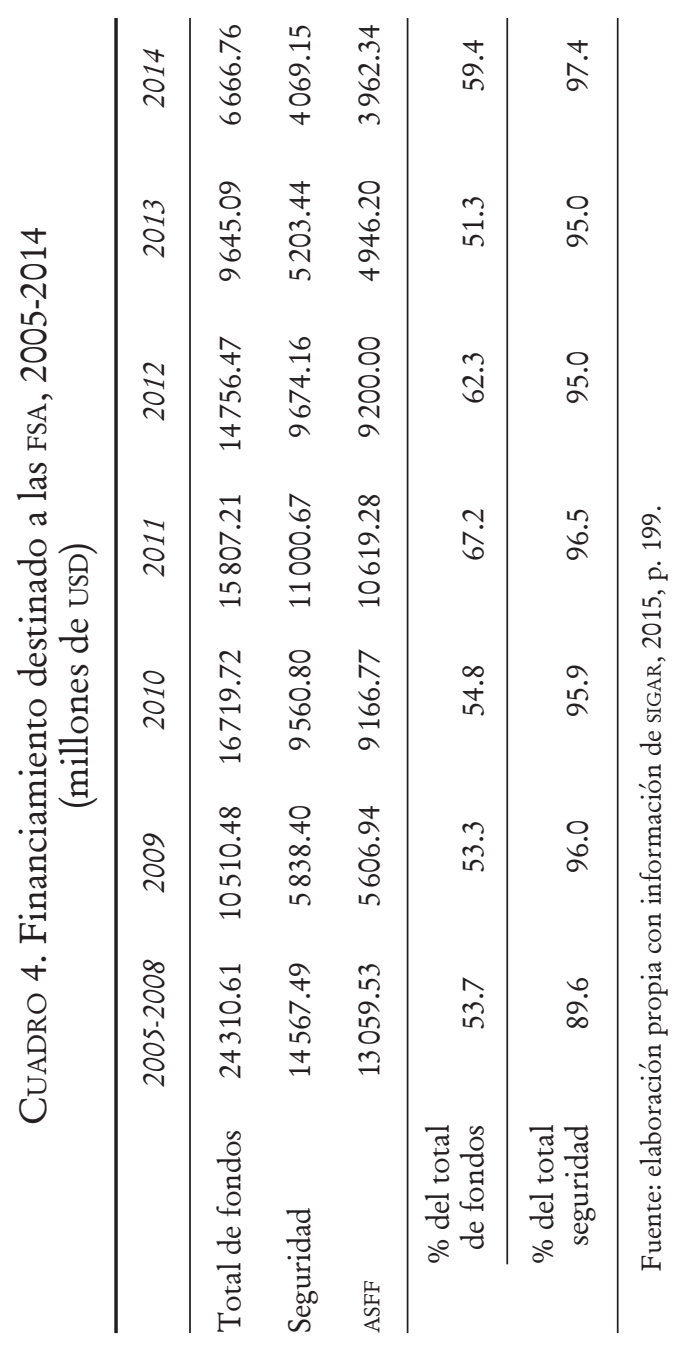


al rubro de seguridad. Con la administración Obama, esa elevada proporción creció todavía más a pesar del significativo incremento de los montos de la asistencia financiera. De 2009 a 2012, el gobierno de Estados Unidos otorgó a las FSA recursos por 34593.99 millones de dólares, 2.6 veces más que en los cuatro años anteriores, lo que equivalió a casi $60 \%$ de toda la asistencia financiera y a $96 \%$ de la asignada a seguridad. El crecimiento numérico de las FSA y el significativo incremento del financiamiento en el periodo 2009-2012 reflejan con claridad el interés de la Casa Blanca en acelerar la preparación de las FSA como premisa para emprender el cronograma previsto de transferencia gradual de poderes.

El acuerdo entre la OTAN y el gobierno afgano para el isteqal, palabra que en pasto y dari significa transición, fue suscrito en 2010 y anunciado oficialmente en la Cumbre de la OTAN celebrada en Lisboa en el verano de ese año (OTAN, 2010). Aunque el proceso de transición aspiraba en teoría a que el liderazgo afgano asumiera un pleno control sobre el gobierno y el desarrollo del país, en la práctica se centró en el ámbito de la seguridad, y las cuestiones relativas a la gobernabilidad y el desarrollo tuvieron una importancia mucho menor (Jalal, 2014, pp. 2-3). El acuerdo estableció los términos y la agenda para la transferencia gradual de las responsabilidades a las FSA. Para su implementación se creó una comisión bipartita -Join Afghan-Nato Inteqal Board- encargada de recomendar, luego de una evaluación previa, las provincias, los distritos y las ciudades que reunían las condiciones para emprender la transición y quedar bajo la responsabilidad de las Fuerzas de Seguridad Afganas.

El acelerado proceso de traspaso se realizó en cinco etapas (OTAN, 2015). El presidente Hamid Karzai anunció el inicio de la primera etapa el 22 de marzo de 2011, tres meses antes de que concluyera la ofensiva de las FIAS, y su alcance se limitó a Kabul y otras pocas regiones con un peso de $20-25 \%$ de la población total. La segunda etapa comenzó a finales de noviembre de ese año y se prolongó hasta mayo de 2012. Para ese entonces, alrededor de $50 \%$ de la población quedó bajo la protección de las FSA. En el transcurso de la tercera etapa, proclamada el 13 de mayo de 2012, la transición se amplió a las 34 provincias y sus capitales, y pasaron al control de las FSA las dos terceras par- 
tes de los distritos del país y 75\% de la población. Como se observa en el cuadro 2, a partir de este momento el proceso estuvo cada vez más acompañado por la reducción progresiva de las tropas de Estados Unidos y las FIAS. La cuarta etapa se desarrolló durante el primer semestre de 2013 y en ella se completó el proceso de transición en 23 de las 34 provincias del país, donde se concentraba $87 \%$ de la población. Finalmente, el 18 de junio de 2013, el presidente afgano anunció el arranque de una quinta etapa para completar el traspaso en las 11 provincias restantes, en su mayoría de la región sur-sureste del país, y colocar a $100 \%$ de la población bajo la responsabilidad de su gobierno.

Desde la perspectiva de Estados Unidos, la viabilidad del plan de salida requería además resolver dos complicaciones importantes. La primera era la solución de la crisis con Pakistán iniciada en 2011. La tendencia a la reactivación empezó a ser más visible después del cambio de gobierno en Islamabad y la llegada al poder del primer ministro Nawaz Sharif en mayo de 2013. La desconfianza de fondo no quedó resuelta, pero la proximidad de la retirada militar de Afganistán y la conveniencia mutua de evitar las impredecibles consecuencias de un descarrilamiento del proceso empujaron a retomar la colaboración, sobre todo de un gobierno pakistaní cada vez más preocupado ante el creciente deterioro del orden interno provocado por la beligerancia del TTP y la violencia del sectarismo religioso (Musthtaq, 2013).

La segunda complicación estaba relacionada con el estancamiento del Acuerdo de Seguridad Bilateral (ABS), que debía estipular los compromisos de Estados Unidos con la seguridad afgana en el escenario post-2014 (Sutika, 2013). El ABS empezó a negociarse en 2012 con la expectativa de que estuviera firmado a más tardar hacia finales de 2013 , pero debido a las diferencias entre Hamid Karzai y la administración Obama, el presidente afgano acabó por negarse a suscribir el acuerdo y dejarle la responsabilidad al sucesor que saldría de las elecciones previstas para abril de 2014 (Neumann, 2015, pp. 6-14). Sin embargo, la firma se dilató una vez más por la crisis política derivada del fraudulento proceso electoral que paralizó por varios meses al gobierno afgano. Debido a la mediación del secretario de 
Estado John Kerry, se consiguió resolver la crisis a finales de septiembre con la creación de un gobierno de unidad y la división de poderes entre los dos candidatos en pugna, Ashrar Ghani y Abdullah Abdullah. Sólo después del reconocimiento de Ashrar Ghani como nuevo presidente afgano, el ABs pudo finalmente firmarse apenas tres meses antes de su fecha de entrada en vigor.

El ABS refrendó el compromiso de Washington de continuar contribuyendo financieramente a la preparación, el equipamiento y el sostenimiento de las FSA, y a mantener una pequeña fuerza de 9800 soldados durante 2015, dedicada esencialmente a funciones de entrenamiento, que sería reducida a 5000 efectivos para fines del siguiente año. Después de 2016, la presencia militar estaría limitada a 1000 efectivos bajo la autoridad de la embajada en Kabul, con la misión de proteger las instalaciones de Estados Unidos y entrenar personal afgano (Katzman y Thomas, 2017, p. 26). ${ }^{4}$ Con la firma del ABS, la administración Obama concretó el último eslabón de una estrategia orientada a garantizar una transición responsable y de bajo riesgo, aunque esas aspiraciones, como se demostrará a continuación, podían soportar poco el peso del escrutinio (Lynch III, 2015).

\section{Resultados de la estrategia militar: análisis de indicadores}

En este apartado trataré de evaluar los resultados de la estrategia militar a través del análisis de varios indicadores que dan una idea del éxito alcanzado, al contrastarlos con los objetivos propuestos en el momento de su formulación. En este sentido, conviene precisar el presupuesto de referencia para el ejercicio de "medición", que puede resumirse de la siguiente manera: si el surge cumplió su cometido original, eso significaría que

${ }^{4}$ Para los fines de este artículo, la referencia al ABS se limita a los términos iniciales acordados al cierre de 2014. Desde principios de 2015, la situación de seguridad obligó al presidente Obama a realizar reiterados ajustes en el calendario previsto para la reducción de las tropas y en el alcance de sus funciones; véase Katzman y Thomas, 2017, pp. 27-28. 
la amenaza representada por Al Qaeda y el talibán logró ser efectivamente contenida; y si se agrega el papel de unas FSA mejor preparadas y capaces de preservar el nivel de contención, entonces la combinación de ambas variables debió ejercer un efecto muy positivo en las condiciones de seguridad que se vería reflejado en un mejoramiento progresivo de los indicadores de violencia y seguridad después de 2011.

Sin embargo, la información derivada de los indicadores seleccionados apunta en una dirección muy diferente. El primero se refiere al número de incidentes de seguridad por año. Este indicador recoge la cantidad de acciones violentas ocurridas por año en todas sus modalidades, en particular las tres más importantes: choques armados directos, ataques suicidas y artefactos explosivos improvisados (IED por sus siglas en inglés). El cuadro 5 muestra la evolución de los incidentes de seguridad a través de dos conceptos comparativos específicos: promedio mensual de acciones violentas en cada año del periodo 20082016 y cantidad de incidentes registrados durante las campañas de primavera-verano, periodo de mayor concentración de beligerancia debido al carácter estacional que las condiciones geográficas y climatológicas imponen al conflicto afgano.

En 2008, cuando el deterioro de la seguridad en Afganistán se convirtió en un punto importante del debate presidencial en Estados Unidos, el promedio mensual de incidentes violentos había alcanzado la cifra de 741, la más alta desde el derrocamiento del talibán en 2001. En el primer año de la administración Obama, la media mensual alcanzó un nuevo récord al subir casi $30 \%$, y en los dos años siguientes registró un incremento espectacular. Lo mismo ocurrió con las acciones violentas en el periodo de mayo-agosto, que llegaron a 5632 en 2010 y a 7482 en 2011, cerca del triple de los incidentes reportados en 2008. Ese aumento, sin embargo, resulta fácilmente explicable porque coincide con el momento del surge, es decir, del acrecentamiento militar y del lanzamiento de la ofensiva contra el talibán, por lo que resulta comprensible que los incidentes de seguridad alcanzaran un número sin precedentes en el bienio 2010-2011. De acuerdo con los objetivos de la estrategia, ese momento debió marcar el clímax que dio paso a una sensible reversión de la tendencia, pero como se aprecia en el cua- 


\section{Cuadro 5. Cantidad de incidentes de seguridad en Afganistán (2008-2016)}

$\begin{array}{lllllllll}2008 & 2009 & 2010 & 2011 & 2012 & 2013 & 2014 & 2015 & 2016\end{array}$

Promedio mensual de incidentes de seguridad $\begin{array}{lllllllll}741 & 960 & 1576 & 1995 & 1462 & 1676 & 1830 & 1886 & 1976\end{array}$

Número de incidentes en mayo/agosto $2650 * 3433 * 5636 * 748253175922 \quad 6212 \quad 57145996$

* Estimación propia calculada a partir de la media del peso porcentual que tuvieron los incidentes de seguridad del periodo mayo-agosto en los años siguientes.

Fuente: elaboración propia con información extraída de ONU, 2009-2017.

dro 5, las cifras de los años 2012-2014 reflejan un escenario muy diferente.

En 2012, ambos conceptos disminuyeron respecto al año anterior, pero siguieron muy altos en comparación con los niveles de 2009, cuando la situación ya era considerada altamente peligrosa. Más aun, la disminución de ese año no marcó el inicio de una tendencia descendente, como demuestra el repunte experimentado posteriormente. Con excepción de 2011, las cifras de incidentes de seguridad en 2013 y 2014 fueron las más altas registradas durante los 13 años de ocupación militar. La campaña de mayo-agosto de 2014 fue más intensa incluso que las de 2015 y 2016 con 6212 incidentes registrados, y el promedio mensual de acciones violentas se mantuvo en niveles muy parecidos. ${ }^{5}$

${ }^{5}$ Sin embargo, sobre todo en 2015 , valdría la pena matizar esa afirmación con la mención de dos cuestiones coyunturales que, si bien resulta imposible cuantificar su peso específico, seguramente afectaron la intensidad de las acciones del talibán durante la campaña de primavera-verano. La primera fue la irrupción del Estado Islámico en el escenario afgano y la proclamación simbólica, como parte del Califato, de la provincia de Jorasán a principios de 2015. Aunque el talibán retuvo su posición de fuerza predominante, la presencia de Dáesh provocó deserciones en sus filas, especialmente en algunos mandos medios, y condujo a choques armados por la disputa de influencia en varias zonas del país. La segunda fue la ruptura interna por la lucha de sucesión dentro del movimiento. La crisis estalló en julio de 2015, cuando el servicio de inteligencia afgano reveló la noticia de que el mulá Omar había muerto 
GRÁFICA 3. Efectivos muertos de Estados Unidos y de las Fuerzas de Seguridad Afganas (FSA)

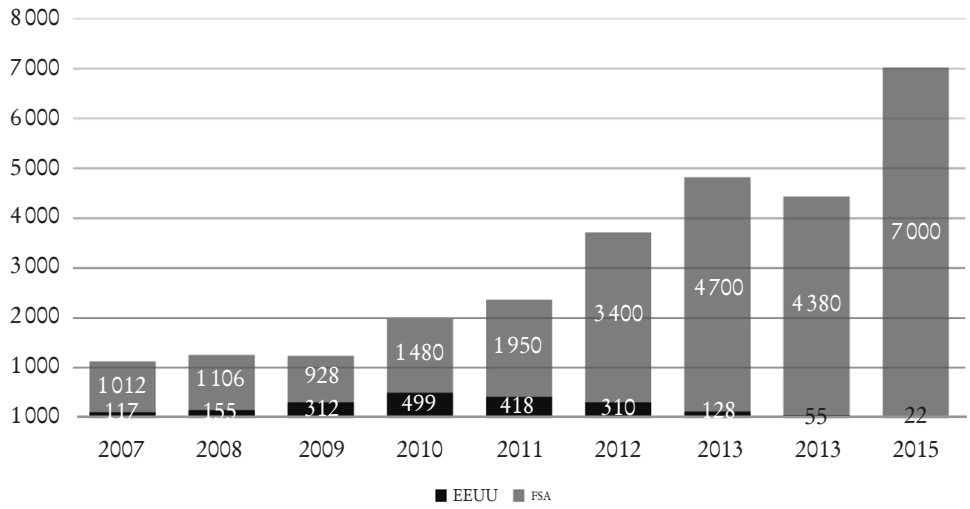

Fuente: elaborado con información de Livingston y O'Hanlon, 2017, pp. 10, 13.

Los datos anteriores confirman la continuidad de una tendencia al deterioro de la seguridad después de 2011, es decir, luego de concluida la ofensiva de las FIAS, comportamiento que guarda una clara correlación con el incremento del número de bajas de las fuerzas gubernamentales en el mismo periodo. La gráfica 3 compara las pérdidas de las tropas estadounidenses y de las FSA causadas por todas las modalidades de acciones violentas durante el periodo 2007-2015.

En 2007-2008, el monto total de bajas de ambas fuerzas promedió unos 1200 efectivos por año. La cifra global se mantuvo más o menos al mismo nivel en 2009, pero el número de muertos estadounidenses se duplicó respecto al año anterior, lo que refleja el cambio provocado por el nuevo esfuerzo militar de la administración Obama. En 2010-2011 se aprecia

desde 2013 en una clínica pakistaní. Varias figuras de la alta dirección del talibán se opusieron a reconocer el liderazgo del mulá Akhtar Mansoor, colaborador más cercano del mulá Omar y quien en su nombre había seguido dirigiendo la organización con el supuesto apoyo de la inteligencia pakistaní. Al final, la mayoría reconoció su autoridad, incluido el primogénito del mulá Omar, pero entre julio y septiembre de 2015 , la crisis produjo escisiones y choques armados entre facciones que afectaron la capacidad operativa del movimiento. 
un incremento significativo de bajas progubernamentales que corresponde al momento de mayor intensidad de las acciones de contrainsurgencia lanzadas conjuntamente por las FIAS y las FSA. A partir de 2012, sin embargo, resulta evidente el contraste entre el rápido decrecimiento de las bajas estadounidenses como efecto natural del proceso de isteqal, y el alarmante incremento de las pérdidas fatales afganas. Las FSA perdieron 3400 efectivos en 2012, tantos como en los dos años anteriores juntos, cuando supuestamente se había librado una campaña decisiva contra el talibán. En 2013, la cifra alcanzó un récord de 4700 bajas, y en 2014, a pesar de una pequeña reducción, la cantidad de 4380 muertos superó a la del trienio 2009-2011. El fuerte incremento de 2015 , por lo tanto, sólo remarcó la tendencia en curso durante los tres años anteriores.

El significativo aumento de bajas afganas no sólo confirma la intensidad de una persistente beligerancia en los años 20122014, sino que también refleja las serias fallas de la segunda premisa de la estrategia, es decir, la preparación de las FSA. El crecimiento del ENA en 2009-2014 estuvo sujeto a dos grandes presiones: el agravamiento sostenido de la situación de seguridad y la necesidad del traspaso de las responsabilidades de la defensa. El efecto combinado de esos factores coadyuvó a poner el énfasis en el aspecto cuantitativo del crecimiento. En apenas dos años, 2009-2010, el ENA duplicó sus efectivos en comparación con 2008, y en seis años la cifra casi se triplicó. Pero ese crecimiento numérico estuvo asociado a fallas cualitativas que impidieron potenciar su impacto real y sembraron incertidumbre en las posibilidades de esa fuerza para garantizar la seguridad del país en el futuro.

La pobre capacidad combativa mostrada en el terreno reflejaba las dificultades del proceso de preparación militar: periodos muy cortos de entrenamiento, elevadísimo índice de analfabetismo entre los reclutados, insuficiencia de instructores, falta de equipamiento, escasa infraestructura militar y total dependencia logística de las fuerzas multinacionales. Las fallas en la preparación, aunadas al aumento del riesgo, los bajos e irregulares salarios, y las difíciles condiciones de la vida militar, convirtieron la deserción en un grave problema para el sostenimiento de las FSA. En 2009-2014, el índice de deserción osciló 
GrÁFICA 4. Efectivos de las FIAS y el ENA, 2008-2014

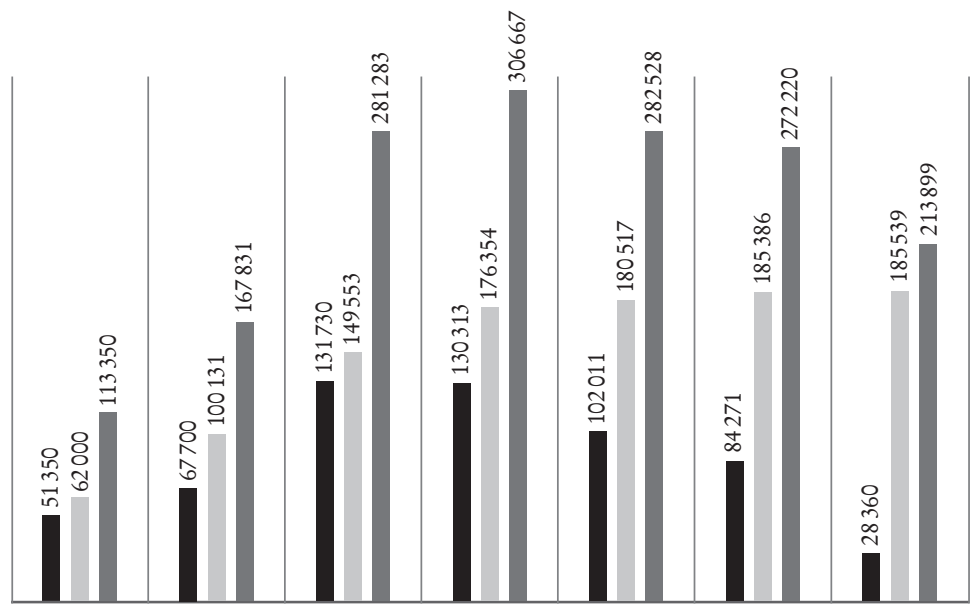

Fuente: elaboración propia con datos de OTAN (2017) y SIGAR (2010, p. 60; 2011, p. 53; 2012, p. 76; 2013, p. 73; 2014a, p. 85; 2014b, p. 92).

entre 25 y 30\%, lo que significó que cada año las FSA estuvieran obligadas a restituir al menos la cuarta parte de sus efectivos (SIGAR, 2013, p. 73; 2014b, p. 89). Ese fenómeno determinó que las cifras oficiales sobre las capacidades de las FSA estuvieran con frecuencia infladas y no reflejaran la cantidad real de efectivos en activo, sobre todo localmente, donde la falta de controles era más evidente (Sopko, 2016, pp. 6-8).

Pero aun considerando las cifras disponibles, el éxito del isteqal parecía poco probable desde el punto de vista militar. De acuerdo con los datos de la gráfica 4, en 2010 la cantidad de efectivos de las fuerzas progubernamentales combinadas creció $40 \%$ respecto al año anterior, y las tropas de las FIAS representaron 46\% de ese total. En 2011, la fuerza militar conjunta rebasó la cifra de los 300000 soldados, de los cuales $42.5 \%$ pertenecía a efectivos de Estados Unidos y la OTAN. Si, como muestran los indicadores analizados, el impacto de esa concentración militar con un poderoso núcleo de tropas extranjeras bien entrenadas y equipadas, con amplio apoyo logístico y férreo control del 
espacio aéreo y las comunicaciones, no bastó para destrozar la capacidad operativa de la insurgencia islamista, resultaba bastante difícil esperar que una fuerza menor, compuesta mayoritariamente de tropas afganas mal preparadas, con deficiente equipamiento y sin autonomía logística, fuera suficiente para asumir el proceso de traspaso y garantizar la seguridad en una geografía tan vasta y compleja. ${ }^{6}$ Sin embargo, una conclusión tan evidente en principio no tuvo al parecer influencia en el curso predeterminado del istegal, ni tampoco en la decisión de la administración Obama de reducir progresivamente los recursos del ASFF destinados al ejército afgano. De un índice 100 en 2011, el financiamiento al ENA bajó a $87 \%$ en 2012, a $46.6 \%$ en 2013 y a $37.3 \%$ en 2014 (cuadro 4).

El índice de víctimas civiles constituye uno de los indicadores más dramáticos de la intensidad de los conflictos armados y su comportamiento siempre guarda una relación directamente proporcional con el nivel de beligerancia e inseguridad imperante. El cuadro 6 muestra la evolución de ese indicador en Afganistán durante el periodo 2009-2016 a partir de dos categorías. La primera engloba el total de víctimas provocadas por las cuatro principales modalidades de violencia registradas en los informes de la ONU (minas, atentados suicidas, artefactos explosivos improvisados y enfrentamientos armados), y la segunda destaca el peso particular de los choques directos dentro de ese total.

La tendencia al agravamiento en este caso refleja la misma consistencia que los indicadores anteriores. En 2010, el total de víctimas civiles creció 20\% respecto al año anterior, y en 2011 la cifra superó en $31.4 \%$ la de 2009. Si bien esos incrementos pudieran en principio considerarse una consecuencia de la

${ }^{6}$ La intensidad de la beligerancia durante la segunda mitad de 2011 y en los años siguientes también permite suponer el pobre efecto real que tuvo sobre el terreno, al menos en el caso afgano, la muerte de Osama bin Laden en mayo de 2011, capitalizada por la administración Obama como un gran triunfo de su estrategia antiterrorista. Esto se explica no sólo por el limitado papel que para entonces el jefe saudí tenía en el ámbito operacional de la organización, sino sobre todo por el peso secundario de Al Qaeda dentro de la insurgencia afgana, con fuertes raíces locales y dominada ampliamente por la fuerza autónoma talibán. Visto en perspectiva, para el éxito de la estrategia en Afganistán fue mucho mayor el daño ocasionado por la crisis con Pakistán, que el impacto positivo que pudo tener la muerte de Osama bin Laden. 


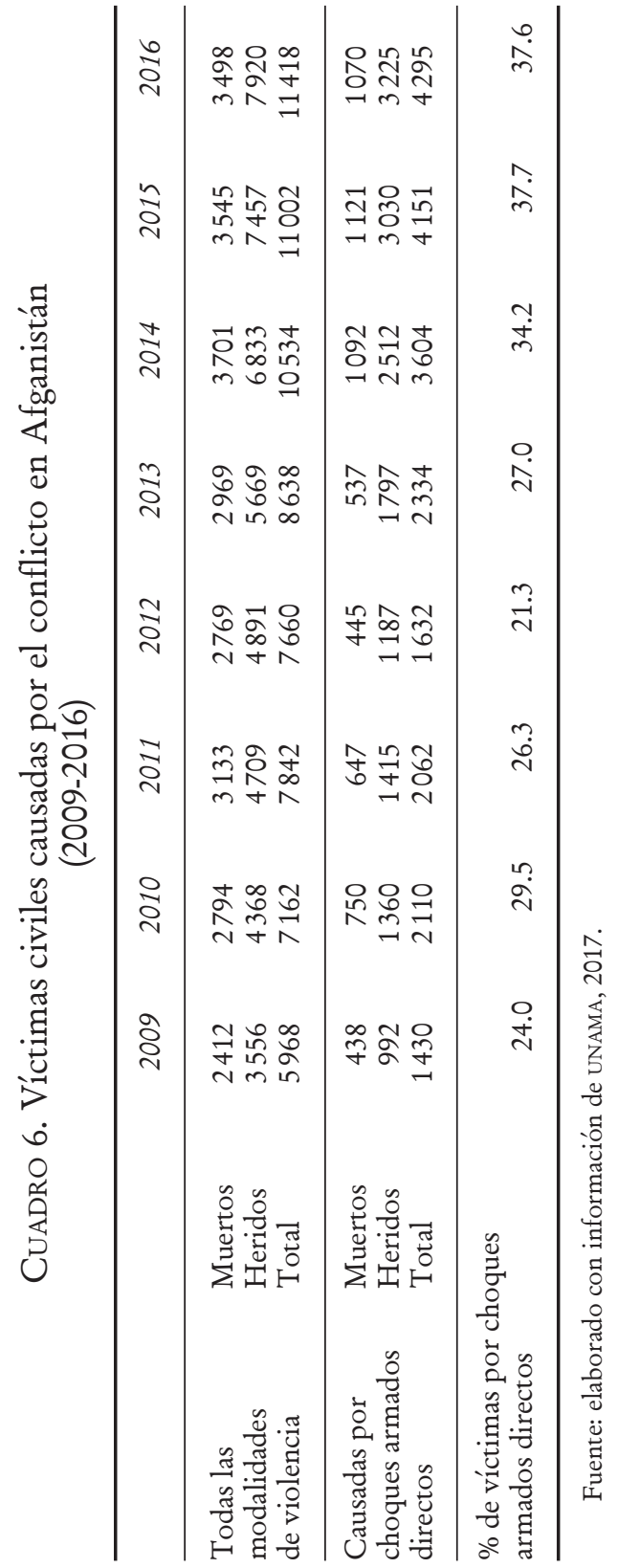


violencia generada por los enfrentamientos entre las fuerzas progubernamentales y la insurgencia durante la campaña 20102011, tampoco en este caso se aprecia un cambio positivo en años posteriores. En 2012, el total de víctimas civiles mostró un comportamiento casi estacionario respecto a 2011 y superior al de 2010, para luego entrar en una brutal espiral de crecimiento. En 2014, año de la culminación del isteqal, el monto de víctimas civiles ascendió a 10534 personas, un incremento de $34 \%$ en comparación con 2011; y de ese total, $34.2 \%$ fue provocado por choques armados directos, lo que representó no sólo la cifra más alta del periodo, sino también el primer año en que esa modalidad de violencia pasó a ser la principal generadora de víctimas civiles en el conflicto. Ese dato es muy revelador del grado de deterioro de la situación de seguridad y refleja que las FIAS dieron por concluida su misión en 2014 sin haber conseguido neutralizar la capacidad militar del talibán, y que las FSA no tenían la capacidad para contener la amenaza que ponía en peligro la estabilidad democrática, la integridad funcional de la sociedad y la protección de los derechos humanos de sus ciudadanos.

La cantidad de refugiados y desplazados internos también es un indicador muy importante que refleja una relación directamente proporcional con la intensidad del conflicto armado, ya que el aumento de la violencia constituye una poderosa fuerza expulsora que genera desplazamientos masivos de personas obligadas a dejar sus lugares de origen por temor a perder sus vidas. En el caso de Afganistán, sin embargo, el indicador de refugiados resulta poco preciso para el propósito particular de este análisis por la imposibilidad de medir su relación específica con la situación de seguridad en el periodo 2009-2014, debido a las dificultades para diferenciar los flujos históricos y económicos a través de la frontera con Pakistán e Irán de los nuevos éxodos migratorios provocados específicamente por la violencia armada. La categoría de repatriados, asociada al mismo proceso, tampoco ofrece confianza, porque en la decisión de regresar a la "madre patria" intervienen muchas variables que no tienen necesariamente relación con la persistencia o no de las condiciones originales que motivaron la expulsión. La cantidad de desplazados internos, en cambio, resulta un 
GRÁFICA 5. Desplazados internos en Afganistán, 2006-2015

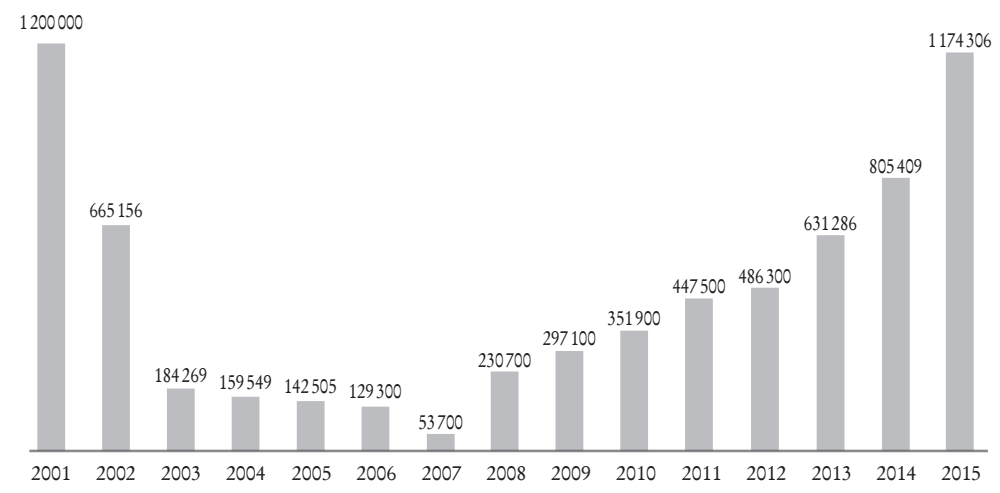

Fuente: elaborado con información de UNHCR, 2018.

indicador mucho más convincente para la demostración de la hipótesis central que nos ocupa.

La gráfica 5 refleja el comportamiento de ese indicador en el periodo 2001-2015. En 2001 había 1200000 desplazados internos en Afganistán, y la mayor parte quedó en esa condición en el último cuatrimestre del año como resultado de la campaña militar de Estados Unidos que condujo al derrocamiento del régimen talibán. Durante los primeros seis años de la transición, la tendencia a la normalización relativa de la situación contribuyó al retorno de muchas familias a sus lugares de origen y la cifra de desplazados internos decreció significativamente hasta su punto más bajo en 2007, con sólo 53700 personas en ese estatus, apenas $4.5 \%$ de las computadas en 2001. A partir de 2008, sin embargo, se aprecia una dramática reversión de esa tendencia debido al creciente deterioro de la seguridad y al aumento de la beligerancia de la insurgencia talibán en las regiones del sur-sureste del país.

En el pináculo de la estrategia militar de la administración Obama (2009-2011), el aumento sucesivo en la cantidad de desplazados alcanzó los niveles más altos del periodo postalibán, con excepción del año 2002, pero ese incremento, explicable por el recrudecimiento del esfuerzo militar en ese trienio, tampoco contribuyó a modificar positivamente el comportamiento 
tendencial en los años siguientes, como habría de esperarse si la estrategia militar hubiera alcanzado el éxito previsto. A diferencia de los indicadores anteriores, en este caso ni siquiera se aprecia una leve y temporal reducción en 2012, sino que la tendencia es constantemente ascendente. Hacia 2014, la cantidad de desplazados subió a más de 800000 personas, la cifra más alta registrada durante los 13 años de ocupación militar y un testimonio bastante elocuente de la terrible situación de inseguridad que afectaba a la población afgana al momento de la retirada de las fuerzas multinacionales.

El último indicador que resulta interesante sumar al análisis es el referido a la producción de opio, una actividad muy relacionada con el talibán desde su aparición en 1994. Si bien el uso de la adormidera como medio de financiamiento del conflicto afgano se remonta a los tiempos de la yihad antisoviética, el talibán convirtió los recursos provenientes del opio en una fuente de ingresos muy importante, primero para costear la expansión y el funcionamiento de su régimen en la segunda mitad de los noventa, y después para financiar la insurgencia contra el gobierno afgano y las fuerzas multinacionales. Esa asociación convierte la producción de opio en un indicador fundamental para entender hasta qué punto la estrategia de combate al talibán consiguió suprimir o debilitar su base financiera de apoyo.

La gráfica 6 muestra el comportamiento de la producción de opio desde 1994. Del análisis de sus cifras se infieren algunas ideas que vale la pena destacar. En 1994, cuando el talibán apareció en la sureña provincia de Kandahar, la producción de opio en Afganistán era ya considerablemente alta. Aunque esos ingresos cobraron una creciente importancia para el régimen, la producción se mantuvo por debajo de la referencia de 1994, con excepción de 1999, que alcanzó una cifra récord de 4565 toneladas métricas, para luego bajar de manera espectacular hasta 185 toneladas en 2001 como resultado del efecto combinado de los edictos de prohibición del mulá Omar y de la campaña militar de Estados Unidos.

Con el inicio de la transición política, la producción de opio entró en una vertiginosa e inédita tendencia de crecimiento debido a la ineficacia de las estrategias antidrogas de un 
Gráfica 6. Producción de opio en Afganistán (en Tm)

Producción de opio ${ }^{\mathrm{TM}}$

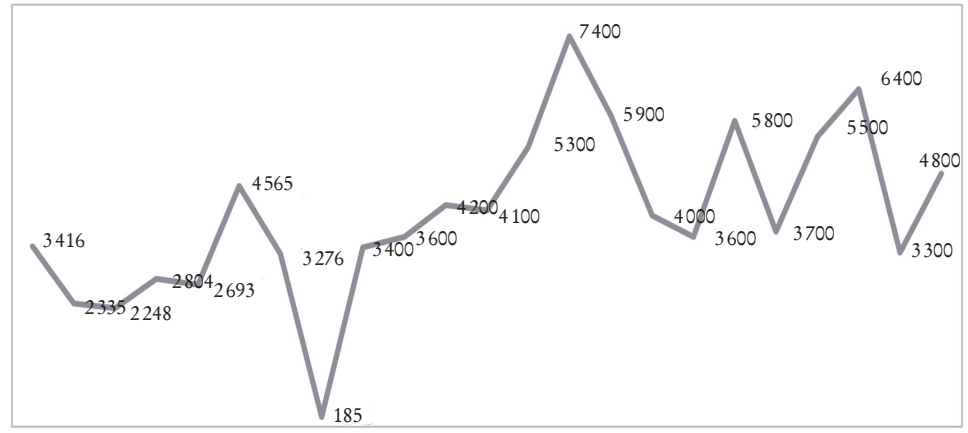

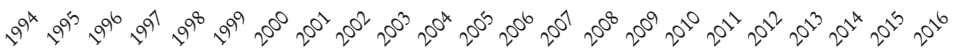

Fuente: elaborado con información de UNODC, 2016.

gobierno afgano incapaz de ejercer un control efectivo sobre gran parte del territorio del país. En seis años, la producción creció hasta un máximo histórico de 7400 toneladas métricas en 2007 . Alrededor de $98 \%$ de esa producción provenía de regiones afectadas por el repunte de la insurgencia talibán, la que por diversos conceptos (impuestos, protección, transportación, control de áreas cultivables y de laboratorios) obtenía ingresos que, según algunas fuentes, rondaban los 500 millones de dólares anuales (Peters, 2009, p. 19). En los tres años siguientes hubo un descenso significativo; sin embargo, los expertos de la UNODC atribuyeron esos resultados más a las afectaciones en los rendimientos por factores coyunturales, como plagas y sequías, que al éxito de las estrategias antinarcóticos. El nuevo pico en la gráfica se aprecia en 2011, cuando la producción se elevó a 5800 toneladas métricas, justo el año en que concluyó la gran ofensiva de las FIAS contra el talibán y se inició el proceso del isteqal.

En 2014, la cantidad de opio alcanzó su segundo mayor registro de la historia con 6400 toneladas métricas, sólo superada por la de 2007. La media anual de producción de opio para los 13 años de ocupación militar fue de 4838 toneladas métricas, 
cifra superior a la del año récord del régimen talibán (1999), dato que refleja el rotundo fracaso de la lucha antidroga y el grado de vulnerabilidad de la transición democrática afgana ante el potencial efecto corrosivo del narcotráfico. En el caso del trienio 2012-2014, la media anual fue todavía mayor, con 5200 toneladas métricas. Esas cifras indican que si la insurgencia talibán pudo mantener y acrecentar su beligerancia, a pesar de la presión de las fuerzas de Estados Unidos y la OTAN, fue porque la estrategia fracasó en destruir no sólo su capacidad militar, sino también su sostén financiero. También demuestran que el gobierno afgano, a pesar del surge y del isteqal, seguía enfrentando en el momento de la retirada el mismo desafío relacionado con la imposibilidad de hacer valer una autoridad efectiva sobre muchas zonas del país.

\section{Conclusiones}

Al inicio del trabajo se afirmó que el grave deterioro de la seguridad en Afganistán en el contexto post-2014 fue un resultado inevitable del fracaso del plan de salida de Estados Unidos, porque la estrategia militar diseñada por la administración Obama falló en el propósito de asegurar las premisas básicas para que el proceso de traspaso de responsabilidades al gobierno afgano se efectuara en un escenario de estabilidad y seguridad relativamente consolidado. Los indicadores analizados confirman de manera contundente esa aseveración y delinean en conjunto un escenario bastante adverso para la viabilidad de una transición supuestamente responsable y de bajo riesgo.

El éxito de la estrategia adoptada descansaba en la consecución del efecto secuencial definido con los términos surge, transition y drawdown. Los resultados del primer momento constituían la base para la ejecución de los otros dos. En ese sentido, el esfuerzo militar desplegado entre enero de 2010 y junio de 2011 debió garantizar dos objetivos esenciales para que el traspaso a las autoridades afganas y la reducción de las fuerzas internacionales transcurrieran en un ambiente de control y estabilidad interna. El primero era conseguir una avasalladora superioridad militar capaz de contener y neutralizar las ame- 
nazas que ponían en riesgo la supervivencia del Estado afgano. El segundo era dotar a ese Estado de la capacidad de respuesta necesaria para preservar la contención de las amenazas, garantizar la integridad funcional de la sociedad, proteger los derechos humanos de sus ciudadanos y asegurar el camino hacia la consolidación democrática que, a fin de cuentas, constituía la gran aspiración del proceso de transición política iniciado en 2002 tras el derrocamiento del régimen talibán.

De acuerdo con esa lógica, las condiciones de seguridad debieron experimentar una significativa mejoría a partir de la segunda mitad de 2011 como resultado del efecto combinado de la concreción de ambos objetivos. Sin embargo, los indicadores analizados coinciden en reflejar que la situación de seguridad en el país siguió estando seriamente comprometida durante 2012, 2013 y 2014. De la correlación de esos datos se pueden derivar tres conclusiones importantes.

La primera es que el surge no logró destruir, como era su propósito, la capacidad operativa del talibán, en parte quizá porque éste optó por enfrentar la superioridad militar de las fuerzas multinacionales con medios de lucha más asimétricos, como se infiere de la preeminencia mostrada por las modalidades de atentados suicidas y artefactos explosivos improvisados en la cantidad de incidentes violentos y muertes civiles reportadas durante los años 2009-2011. La segunda es que, a pesar de su acelerado crecimiento, las FSA no tenían la capacidad suficiente para enfrentar el peligro de la insurgencia talibán ni para imponer una autoridad real en todo el territorio del país, considerando que el efecto del surge, al parecer, condujo más a un repliegue táctico de las fuerzas antigubernamentales que a la contención efectiva de esa amenaza, como se desprende del visible incremento mostrado por los choques armados directos a partir de 2012 y que hacia 2014 se convirtieron en la modalidad predominante entre los incidentes de seguridad registrados. $\mathrm{La}$ tercera conclusión es que, al no conseguir las premisas básicas para asegurar el efecto secuencial de la estrategia, el proceso del isteqal y la reducción gradual de los efectivos de las FIAS se instrumentaron a pesar de la persistencia de un entorno de seguridad seriamente deteriorado, que hacía poco probable la consumación de una transición de bajo riesgo. 
Desde esa perspectiva, el agravamiento de la violencia y la inseguridad que ha caracterizado el escenario afgano post-2014 no constituye un fenómeno nuevo, sino que forma parte de una misma tendencia de continuidad claramente establecida desde los años previos a la retirada de Afganistán de las fuerzas militares de la OTAN y de Estados Unidos.

Dirección institucional del autor:

División de Ciencias Politicas y Humanidades

Universidad de Quintana Roo

Boulevard Bahía s/ $n$, col. Del Bosque.

C.P. 77019, Chetumal, Quintana Roo, México.

\section{Referencias}

BALDwIN, D. A. (1997). The concept of security. Review of International Studies, 23(1), 5-26. Recuperado de https://www.cambridge. org/core/services/aop-cambridge-core/content/view/67188B 6038200A97COB0A370FDC9D6B8/S0260210597000053a.pdf/ concept_of security.pdf

BALTAR, E. (2018). Estados Unidos y Pakistán en la guerra contra el terrorismo: disimetría y conflicto de intereses geopolíticos. Estudios de Asia y África, 53(3), 501-536. https://dx.doi.org/10.24201/ eaa.v53i3.2329

Gul, I. (2009). The most dangerous place. Pakistan's lawless frontier. Nueva York, NY: Viking.

Jalal, M. (2014). Transition to Afghan control in 2014. Perspectives from subnational level in Afghanistan. Kabul: Integrity Watch Afghanistan. Recuperado de https://iwaweb.org/wp-content/ uploads/2014/12/transition_to_afghan_control_in_2014.pdf

JaLaLI, A. A. (2016). Afghanistan national defense and security forces. Washington, DC: Unites States Institute of Peace. Recuperado de https://www.usip.org/sites/default/files/PW115-AfghanistanNational-Defense-and-Security-Forces-Mission-Challenges-andSustainability.pdf

Joscelyn, T. y Roggio, B. (21 de octubre de 2015). Are we losing Afghanistan again? New York Times. Recuperado de https:// www.nytimes.com/2015/10/21/opinion/are-we-losing-afghanistan-again.html 
Katzman, K. y Thomas, C. (2017). Afghanistan: Post-Taliban governance, security, and U.S. policy. (Report RL30588). Washington, D.C.: Congressional Research Service. Recuperado de https:// fas.org/sgp/crs/row/RL30588.pdf

Livingston, I. S. y O'Hanlon, M. (25 de mayo de 2017). Afghanistan index. Washington, D.C.: Brookings Institution. Recuperado de https://www.brookings.edu/wp-content/uploads/ 2016/07/21csi_20170525_afghanistan_index.pdf

LYNCH III, T. F. (2015). There is still time to keep Afghanistan from going the way of Iraq-if drawdown plans are significantly modified. (E-notes). Washington, D.C.: Foreign Policy Research Institute. Recuperado de https://www.fpri.org/docs/lynch_on_ afghanistan.pdf

Mullah Omar-in his own words (26 de septiembre de 2001). The Guardian. Recuperado de https://www.theguardian.com/ world/2001/sep/26/afghanistan.features11

Musthtaq, N. (2013). Impact of terrorism on Pakistan. Strategic Studies, 33(2), 33-68. Recuperado de http://issi.org.pk/wp-content/ uploads/2014/06/1393573242_59579987.pdf

NAWAZ, S. (2009). FATA - A most dangerous place: Meeting the challenge of militancy and terror in the federally administered tribal areas of Pakistan. Washington, D.C.: Center for Strategic and International Studies. Recuperado de https://csis-prod.s3.amazonaws. com/s3fs-public/legacy_files/files/media/csis/pubs/081218 nawaz_fata_web.pdf

Neumann, R. E. (2015). Failed relations between Hamid Karzai and the United States. What can we learn? (Special Report 373). Washington, D.C.: United States Institute of Peace. Recuperado de https://www.usip.org/sites/default/files/SR373-FailedRelations-between-Hamid-Karzai-and-the-United-States.pdf

Овама, B. (4 de junio de 2009a). Remarks by the President on a new beginning. Washington, D.C.: Office of the Press Secretary. Recuperado de https://obamawhitehouse.archives.gov/thepress-office/remarks-president-cairo-university-6-04-09

Овама, B. (1 de diciembre de 2009b). Remark by the President in address to the nation on the way forward in Afghanistan and Pakistan. Washington, D.C.: Office of the Press Secretary. Recuperado de https://obamawhitehouse.archives.gov/the-press-office/ remarks-president-address-nation-way-forward-afghanistan-andpakistan

Organización de las Naciones Unidas. (23 de septiembre de 2008). Informe del secretario general sobre la situación en el Afganistán y 
sus consecuencias para la paz y la seguridad internacionales: informe del secretario general (A/63/372-S/2008/617). Recuperado de https://undocs.org/es/S/2008/617

Organización de las Naciones Unidas. (10 de marzo de 2009). La situación en el Afganistán y sus consecuencias para la paz y la seguridad internacionales: informe del secretario general (A/63/751S/2009/135). Recuperado de https://undocs.org/es/S/2009/135 Organización de las Naciones Unidas. (22 de septiembre de 2009). La situación en el Afganistán y sus consecuencias para la paz y la seguridad internacionales: informe del secretario general (A/64/364S/2009/475). Recuperado de https://undocs.org/es/S/2009/475

Organización de las Naciones Unidas. (10 de marzo de 2010). La situación en el Afganistán y sus consecuencias para la paz y la seguridad internacionales: informe del secretario general (A/64/705S/2010/127). Recuperado de https://undocs.org/es/s/2010/127 Organización de las Naciones Unidas. (14 de septiembre de 2010). La situación en el Afganistán y sus consecuencias para la paz y la seguridad internacionales: informe del secretario general (A/64/911S/2010/463). Recuperado de https://undocs.org/es/s/2010/463 Organización de las Naciones Unidas. (9 de marzo de 2011). La situación en el Afganistán y sus consecuencias para la paz y la seguridad internacionales: informe del secretario general (A/65/783S/2011/120). Recuperado de https://undocs.org/es/s/2011/120 Organización de las Naciones Unidas. (21 de septiembre de 2011). La situación en el Afganistán y sus consecuencias para la paz y la seguridad internacionales: informe del secretario general (A/66/369S/2011/590). Recuperado de https://undocs.org/es/s/2011/590 Organización de las Naciones Unidas. (5 de marzo de 2012). La situación en el Afganistán y sus consecuencias para la paz y la seguridad internacionales: informe del secretario general (A/66/728S/2012/133). Recuperado de https://undocs.org/es/s/2012/133 Organización de las Naciones Unidas. (13 de septiembre de 2012). La situación en el Afganistán y sus consecuencias para la paz y la seguridad internacionales: informe del secretario general (A/67/354S/2012/703). Recuperado de https://undocs.org/es/s/2012/703 Organización de las Naciones Unidas. (5 de marzo de 2013). La situación en el Afganistán y sus consecuencias para la paz y la seguridad internacionales: informe del secretario general (A/67/778S/2013/133). Recuperado de https://undocs.org/es/S/2013/133 Organización de las Naciones Unidas. (6 de septiembre de 2013). La situación en el Afganistán y sus consecuencias para la paz y la seguridad internacionales: informe del secretario general (A/68/609- 
S/2013/535). Recuperado de https://undocs.org/es/S/2013 $/ 535$

Organización de las Naciones Unidas. (7 de marzo de 2014). La situación en el Afganistán y sus consecuencias para la paz y la seguridad internacionales: informe del secretario general (A/68/789S/2014/163). Recuperado de http://undocs.org/es/S/2014/163 Organización de las Naciones Unidas. (9 de septiembre de 2014). La situación en el Afganistán y sus consecuencias para la paz y la seguridad internacionales: informe del secretario general (A/69/540S/2014/656). Recuperado de http://undocs.org/es/S/2014/656 Organización de las Naciones Unidas. (27 de febrero de 2015). La situación en el Afganistán y sus consecuencias para la paz y la seguridad internacionales: informe del secretario general (A/69/801S/2015/151). Recuperado de http://undocs.org/es/S/2015/151 Organización de las Naciones Unidas. (1 de septiembre de 2015). La situación en el Afganistán y sus consecuencias para la paz y la seguridad internacionales: informe del secretario general (A/70/359S/2015/684). Recuperado de http://undocs.org/es/S/2015/684 Organización de las Naciones Unidas. (7 de marzo de 2016). La situación en el Afganistán y sus consecuencias para la paz y la seguridad internacionales (A/70/775S/2016/218). Recuperado de https:// undocs.org/es/S/2016/218

Organización de las Naciones Unidas. (7 de septiembre de 2016). La situación en el Afganistán y sus consecuencias para la paz y la seguridad internacionales: informe del secretario general (A/71/616S/2016/768). Recuperado de http://undocs.org/es/S/2016/768 Organización de las Naciones Unidas. (3 de marzo de 2017). La situación en el Afganistán y sus consecuencias para la paz y la seguridad internacionales: informe del secretario general (A/71/826S/2017/189). Recuperado de http://undocs.org/es/S/2017/189 Organización del Tratado del Atlántico Norte. (20 de noviembre de 2010). Lisbon Summit Declaration. Issued by the Heads of State and Government participating in the meeting of the North Atlantic Council in Lisbon. Recuperado de https://www.nato.int/cps/ en/natohq/official_texts_68828.htm

Organización del Tratāo del Atlántico Norte. (7 de enero 2015). Inteqal: Transition to Afghan lead. Recuperado de http://www. nato.int/cps/ua/natohq/topics_87183.htm

Organización del Tratado del Atlántico Norte. (2017). NATO and Afghanistan. IsAFplacemats archive. Recuperado de https://www. nato.int/cps/en/natolive/107995.htm

Orozco, G. (2006). El concepto de la seguridad en la Teoría de las 
Relaciones Internacionales. Revista CIDOB d'Afers Internationals, (72), 161-180. Recuperado de https://www.cidob.org/es/ media2/publicacions/afers/72/72orozco

Peters, G. (2009). The Taliban and the opium trade. En A. Giustozzi (Ed.), Decoding the new Taliban: Insights from the Afghan field (pp. 7-22). Nueva York, NY: Columbia University Press.

RafiQue, N. (2011). Rethinking Pakistan-U.S. relations. Strategic Studies, 31(3), 124-152. Recuperado de http://issi.org.pk/wpcontent/uploads/2014/06/1328592533_15784080.pdf

SopKo, J. (Special Inspector General for Afghanistan Reconstruction). (12 de febrero de 2016). Assessing the capabilities and effectiveness of the Afghan national defense and security forces. Recuperado de https://www.sigar.mil/pdf/testimony/sigar-16-17-ty.pdf

Special Inspector General for Afghanistan Reconstruction (SIGAR). (30 de enero de 2010). Quarterly Report to the United States Congress. Arlington, VA: SIGAR. Recuperado de https://www.sigar.mil/ pdf/quarterlyreports/2010-01-30qr.pdf

Special Inspector General for Afghanistan Reconstruction. (30 de enero de 2011). Quarterly Report to the United States Congress. Arlington, VA: SIGAR. Recuperado de https://www.sigar.mil/ pdf/quarterlyreports/2011-01-30qr.pdf

Special Inspector General for Afghanistan Reconstruction. (30 de enero de 2012). Quarterly Report to the United States Congress. Arlington, VA: SIGAR. Recuperado de https://www.sigar.mil/ pdf/quarterlyreports/2012-01-30qr.pdf

Special Inspector General for Afghanistan Reconstruction. (30 de enero de 2013). Quarterly Report to the United States Congress. Arlington, VA: SIGAR. Recuperado de https://www.sigar.mil/ pdf/quarterlyreports/2013-01-30qr.pdf

Special Inspector General for Afghanistan Reconstruction. (30 de enero de 2014a). Quarterly Report to the United States Congress. Arlington, VA: sIgAR. Recuperado de https://www.sigar.mil/ pdf/quarterlyreports/2014Jan30QR.pdf

Special Inspector General for Afghanistan Reconstruction. (30 de octubre de 2014b). Quarterly Report to the United States Congress. Arlington, VA: SIGAR. Recuperado de https://www.sigar.mil/ pdf/quarterlyreports/2014-10-30qr.pdf

Special Inspector General for Afghanistan Reconstruction. (30 de enero de 2015). Quarterly Report to the United States Congress. Arlington, VA: SIGAR. Recuperado de https://www.sigar.mil/ pdf/quarterlyreports/2015-01-30qr.pdf

Statista (2018). U.S. war costs in Iraq and Afghanistan from 2003 
to 2015. Recuperado de https://www.statista.com/statistics/ 271526/us-war-costs-in-iraq-and-afghanistan/

SuTIKA, M. (16 de enero de 2013). US-Afghan Security Agreement: Competing notions of sovereignty? (Part I). Centre for Conflict and Peace Studies Afghanistan. Recuperado de http://www. caps.af/Doc/US_AFG_BSA_FINAL.pdf

United Nations Assistance $\bar{M}$ ission in Afghanistan (UNAMA). (2017). Afghanistan. Protection of civilians in armed conflict. Annual report 2016. Recuperado de https://unama.unmissions.org/ sites/default/files/protection_of civilians in_armed_conflict annual_report_2016_final280317.pdf

United Nations High Commissioner for Refugees (UNHCR). (2018). Population Statistics. Recuperado de http://popstats.unhcr.org/ en/time series

United Nations Office on Drugs and Crime (UNODC). (diciembre de 2016). Afghanistan opium survey 2016. Recuperado de https:// www.unodc.org/documents/crop-monitoring/Afghanistan/ Afghanistan_opium_survey_2016_cultivation_production.pdf

Van Kempen, P. H. (2013). Four concepts of security-A human rights perspective. Human Right Law Review, 13(1), 1-23. https:// dx.doi.org/10.1093/hrlr/ngs037 
